\title{
Surgical removal versus retention for the management of asymptomatic disease-free impacted wisdom teeth (Review)
}

Ghaeminia H, Perry J, Nienhuijs MEL, Toedtling V, Tummers M, Hoppenreijs TJM, Van der Sanden WJM, Mettes TG

Ghaeminia H, Perry J, Nienhuijs MEL, Toedtling V, Tummers M, Hoppenreijs TJM, Van der Sanden WJM, Mettes TG. Surgical removal versus retention for the management of asymptomatic disease-free impacted wisdom teeth. Cochrane Database of Systematic Reviews 2016, Issue 8. Art. No.: CD003879. DOI: 10.1002/14651858.CD003879.pub4.

www.cochranelibrary.com 
TABLE OF CONTENTS

HEADER 1

ABSTRACT

PLAIN LANGUAGE SUMMARY

SUMMARY OF FINDINGS

BACKGROUND

OBJECTIVES

METHODS

RESULTS

Figure 1.

DISCUSSION

AUTHORS' CONCLUSIONS

ACKNOWLEDGEMENTS

REFERENCES

CHARACTERISTICS OF STUDIES

ADDITIONAL TABLES

APPENDICES

WHAT'S NEW

HISTORY

CONTRIBUTIONS OF AUTHORS

DECLARATIONS OF INTEREST

SOURCES OF SUPPORT

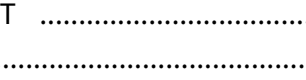

DIFFERENCES BETWEEN PROTOCOL AND REVIEW

INDEX TERMS

1

2

4

6

6

6

9

10

12

14

14

15

17

20

21

23

24

24

24

24

25

25 
[Intervention Review]

\section{Surgical removal versus retention for the management of asymptomatic disease-free impacted wisdom teeth}

Hossein Ghaeminia1,2, John Perry ${ }^{3}$, Marloes EL Nienhuijs ${ }^{1}$, Verena Toedtling ${ }^{4}$, Marcia Tummers ${ }^{5}$, Theo JM Hoppenreijs², Wil JM Van der Sanden 6 , Theodorus G Mettes 7

1Department of Oral and Maxillofacial Surgery, Radboud University Medical Center, Nijmegen, Netherlands. ${ }^{2}$ Department of Oral and Maxillofacial Surgery, Rijnstate Hospital, Arnhem, Netherlands. ${ }^{3}$ Department of Orthodontics, Cardiff University School of Dentistry, Cardiff, UK. ${ }^{4}$ Department of Oral and Maxillofacial Surgery, Division of Dentistry, Faculty of Biology, Medicine and Health, The University of Manchester, Manchester, UK. ${ }^{5}$ Radboud Institute for Health Sciences, Department for Health Evidence, Radboud University Medical Center, Nijmegen, Netherlands. ${ }^{6}$ Department of Quality and Safety of Oral Health Care, College of Dental Science, Radboud University Medical Center, Nijmegen, Netherlands. ${ }^{7}$ The National Institute for Development of Clinical Practices Guidelines in Oral Care (KiMo), Utrecht, Netherlands

Contact address: Hossein Ghaeminia, Department of Oral and Maxillofacial Surgery, Radboud University Medical Center, Geert Grooteplein Zuid 14, Nijmegen, 6525 GA, Netherlands. hos.ghaeminia@gmail.com.

Editorial group: Cochrane Oral Health Group

Publication status and date: New search for studies and content updated (conclusions changed), published in Issue 8, 2016.

Citation: Ghaeminia H, Perry J, Nienhuijs MEL, Toedtling V, Tummers M, Hoppenreijs TJM, Van der Sanden WJM, Mettes TG. Surgical removal versus retention for the management of asymptomatic disease-free impacted wisdom teeth. Cochrane Database of Systematic Reviews 2016, Issue 8. Art. No.: CD003879. DOI: 10.1002/14651858.CD003879.pub4.

Copyright ( 2016 The Cochrane Collaboration. Published by John Wiley \& Sons, Ltd.

\section{A B S T R A C T}

\section{Background}

Prophylactic removal of asymptomatic disease-free impacted wisdom teeth is surgical removal of wisdom teeth in the absence of symptoms and with no evidence of local disease. Impacted wisdom teeth may be associated with pathological changes, such as pericoronitis, root resorption, gum and alveolar bone disease (periodontitis), caries and the development of cysts and tumours. When surgical removal is carried out in older people, the risk of postoperative complications, pain and discomfort is increased. Other reasons to justify prophylactic removal of asymptomatic disease-free impacted third molars have included preventing late lower incisor crowding, preventing damage to adjacent structures such as the second molar or the inferior alveolar nerve, in preparation for orthognathic surgery, in preparation for radiotherapy or during procedures to treat people with trauma to the affected area. Removal of asymptomatic diseasefree wisdom teeth is a common procedure, and researchers must determine whether evidence supports this practice. This review is an update of an existing review published in 2012.

\section{Objectives}

To evaluate the effects of removal compared with retention (conservative management) of asymptomatic disease-free impacted wisdom teeth in adolescents and adults.

\section{Search methods}

We searched the following electronic databases: Cochrane Oral Health's Trials Register (to 24 May 2016), the Cochrane Central Register of Controlled Trials (CENTRAL) (2016, Issue 4), MEDLINE Ovid (1946 to 24 May 2016) and Embase Ovid (1980 to 24 May 2016). We searched ClinicalTrials.gov and the World Health Organization International Clinical Trials Registry Platform for ongoing and unpublished studies to 24 May 2016. We imposed no restrictions on language or date of publication in our search of electronic databases. 


\section{Selection criteria}

Studies comparing removal (or absence) with retention (or presence) of asymptomatic disease-free impacted wisdom teeth in adolescents or adults. We included randomised controlled trials (RCTs) with no restriction on length of follow-up, if available. We considered quasiRCTs and prospective cohort studies for inclusion if investigators measured outcomes with follow-up of five years or longer.

\section{Data collection and analysis}

Eight review authors screened search results and assessed the eligibility of studies for inclusion according to the review inclusion criteria. Eight review authors independently conducted risk of bias assessments in duplicate. When information was unclear, we contacted study authors for additional information.

\section{Main results}

This review includes two studies. The previous review included one RCT with a parallel-group design, which was conducted in a dental hospital setting in the United Kingdom; our new search for this update identified one prospective cohort study conducted in the private sector in the USA.

\section{Primary outcome}

No eligible studies in this review reported the effects of removal compared with retention of asymptomatic disease-free impacted wisdom teeth on health-related quality of life

\section{Secondary outcomes}

We found only low to very low quality evidence of the effects of removal compared with retention of asymptomatic disease-free impacted wisdom teeth for a limited number of secondary outcome measures.

One prospective cohort study, reporting data from a subgroup of 416 healthy male participants, aged 24 to 84 years, compared the effect of the absence (previous removal or agenesis) against the presence of asymptomatic disease-free impacted wisdom teeth on periodontitis and caries associated with the distal of the adjacent second molar during a follow-up period of three to over 25 years. Very low quality evidence suggests that the presence of asymptomatic disease-free impacted wisdom teeth may be associated with increased risk of periodontitis affecting the adjacent second molar in the long term. In the same study, which is at serious risk of bias, there is insufficient evidence to demonstrate a difference in caries risk associated with the presence or absence of impacted wisdom teeth.

One RCT with 164 randomised and 77 analysed adolescent participants compared the effect of extraction with retention of asymptomatic disease-free impacted wisdom teeth on dimensional changes in the dental arch after five years. Participants (55\% female) had previously undergone orthodontic treatment and had 'crowded' wisdom teeth. No evidence from this study, which was at high risk of bias, was found to suggest that removal of asymptomatic disease-free impacted wisdom teeth has a clinically significant effect on dimensional changes in the dental arch.

The included studies did not measure our other secondary outcomes: costs, other adverse events associated with retention of asymptomatic disease-free impacted wisdom teeth (pericoronitis, root resorption, cyst formation, tumour formation, inflammation/ infection) and adverse effects associated with their removal (alveolar osteitis/postoperative infection, nerve injury, damage to adjacent teeth during surgery, bleeding, osteonecrosis related to medication/radiotherapy, inflammation/infection).

\section{Authors' conclusions}

Insufficient evidence is available to determine whether or not asymptomatic disease-free impacted wisdom teeth should be removed. Although asymptomatic disease-free impacted wisdom teeth may be associated with increased risk of periodontitis affecting adjacent second molars in the long term, the evidence is of very low quality. Well-designed RCTs investigating long-term and rare effects of retention and removal of asymptomatic disease-free impacted wisdom teeth, in a representative group of individuals, are unlikely to be feasible. In their continuing absence, high quality, long-term prospective cohort studies may provide valuable evidence in the future. Given the lack of available evidence, patient values should be considered and clinical expertise used to guide shared decision making with patients who have asymptomatic disease-free impacted wisdom teeth. If the decision is made to retain asymptomatic disease-free impacted wisdom teeth, clinical assessment at regular intervals to prevent undesirable outcomes is advisable.

\section{PLAIN LANGUAGE SUMMARY}

\section{Surgical removal versus retention for the management of asymptomatic disease-free impacted wisdom teeth}

\section{Review question}

This review, produced through Cochrane Oral Health, seeks to assess the effects of removal compared with conservative management of impacted wisdom teeth, in the absence of symptoms and without evidence of local disease, in adolescents and adults. This is an update of an existing review published in 2012. 


\section{Background}

Wisdom teeth, or third molars, generally erupt between the ages of 17 and 26 years. These are the last teeth to erupt, and they normally erupt into a position closely behind the last standing teeth (second molars). Space for these teeth to erupt can be limited. Wisdom teeth often fail to erupt or erupt only partially, which is often due to impaction of the wisdom teeth against the second molars (teeth directly in front of the wisdom teeth). In most cases, this occurs when second molars are blocking the path of eruption of third molar teeth and act as a physical barrier, preventing complete eruption. An impacted wisdom tooth is called asymptomatic and disease-free in the absence of signs and symptoms of disease affecting the wisdom tooth or nearby structures.

Impacted wisdom teeth can cause swelling and ulceration of the gums around the wisdom teeth, damage to the roots of second molars, decay in second molars, gum and bone disease around second molars and development of cysts or tumours. General agreement exists that removal of wisdom teeth is appropriate if signs or symptoms of disease related to the wisdom teeth are present. Less agreement exists about the appropriate management of asymptomatic disease-free impacted wisdom teeth.

\section{Study characteristics}

We searched the medical literature up to May 2016 and found one randomised controlled trial (RCT) and one prospective cohort study to include in this review. These studies involved 493 participants in total. The RCT conducted at a dental hospital in the UK included 77 adolescent male and female participants, and the cohort study conducted at a private dental clinic in the USA involved 416 men aged 24 to 84 years.

\section{Key results}

Available evidence is insufficient to show whether or not asymptomatic disease-free impacted wisdom teeth should be removed.

One study at serious risk of bias provided very low quality evidence suggesting that the presence of asymptomatic disease-free impacted wisdom teeth is associated with increased risk of periodontitis (infection of the gums) affecting the adjacent second molar (teeth directly in front of the wisdom teeth) in the long term. In the same study, no evidence was found to suggest that the presence of asymptomatic disease-free impacted wisdom teeth increases the risk of caries affecting the adjacent second molar.

Another study, also at high risk of bias, found no evidence to suggest that removal of asymptomatic disease-free impacted wisdom teeth has an effect on crowding in the dental arch.

The included studies did not measure our primary outcome - health-related quality of life. Nor did they measure our secondary outcomes - costs, other adverse events associated with retention of asymptomatic disease-free impacted wisdom teeth (pericoronitis, root resorption, cyst formation, tumour formation, inflammation/infection) and adverse effects associated with their removal (alveolar osteitis/postoperative infection, nerve injury, damage to adjacent teeth during surgery, bleeding, osteonecrosis related to medication/ radiotherapy, inflammation/infection).

\section{Quality of the evidence}

Evidence provided by the two studies included in this review is of low to very low quality, so we cannot rely on these findings. High-quality research is urgently needed to support clinical practice in this area. In light of the lack of available evidence, patient values should be considered and clinical expertise used when treatment decisions are made with patients who have asymptomatic disease-free impacted wisdom teeth. If the decision is made to retain asymptomatic disease-free impacted wisdom teeth, clinical assessment at regular intervals is advisable to prevent undesirable outcomes. 


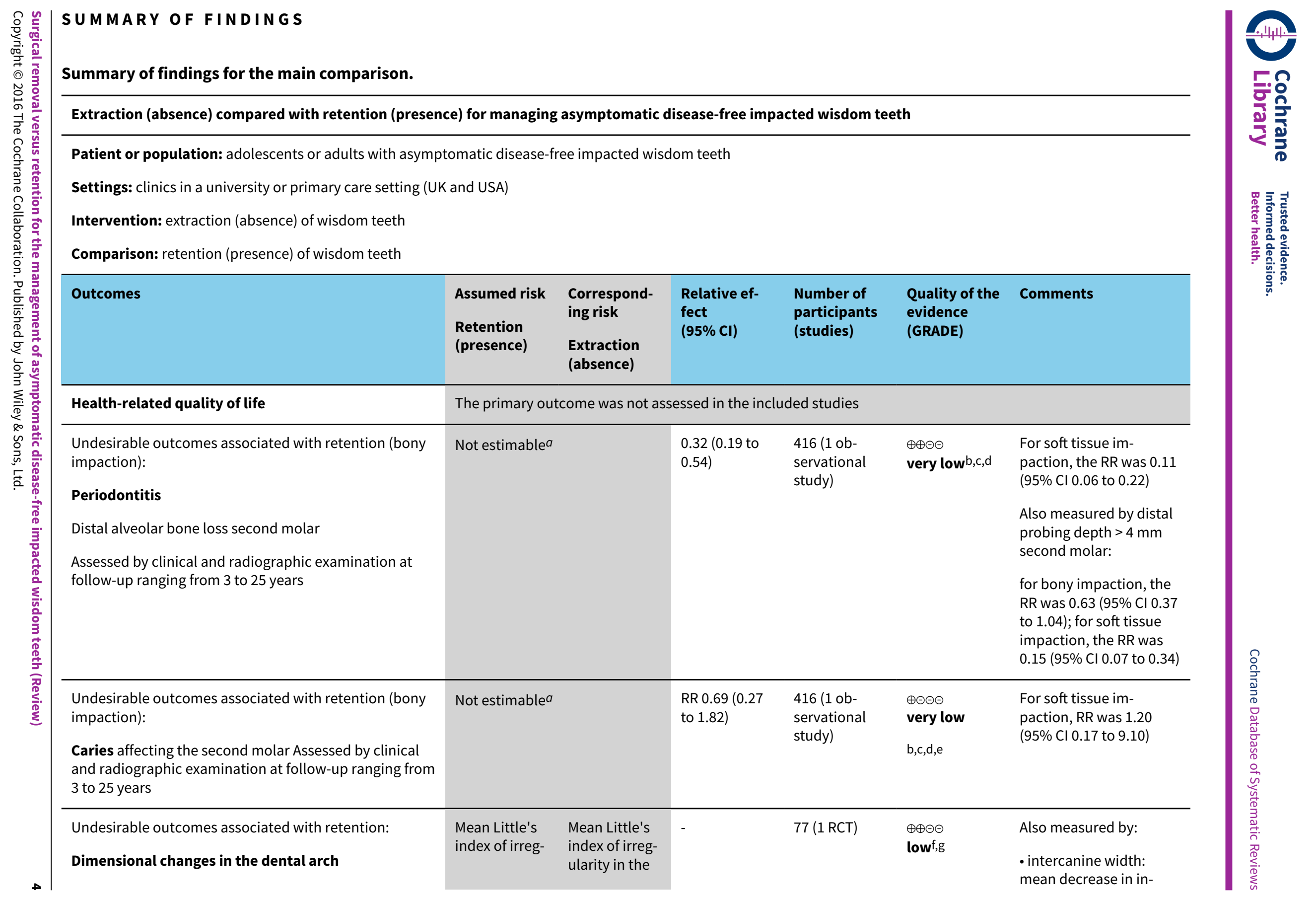


- arch length: mean decrease in arch length in control group was 2.13 $\mathrm{mm}$. Mean decrease in arch length in intervention group was $1.03 \mathrm{~mm}$ lower $(0.56$ lower to 1.5 lower)

\begin{tabular}{ll}
\hline Undesirable outcomes associated with removal & Not measured \\
\hline Costs & Not measured
\end{tabular}

*The basis for the assumed risk (e.g. median control group risk across studies) is provided in footnotes. The corresponding risk (and its $95 \%$ confidence interval) is based on the assumed risk in the comparison group and the relative effect of the intervention (and its $95 \% \mathrm{Cl}$ ). Cl: confidence interval; RR: risk ratio

GRADE Working Group grades of evidence

High quality: Further research is very unlikely to change our confidence in the estimate of effect

Moderate quality: Further research is likely to have an important impact on our confidence in the estimate of effect and may change the estimate

Low quality: Further research is very likely to have an important impact on our confidence in the estimate of effect and is likely to change the estimate Very low quality: We are very uncertain about the estimate

a Results were presented at tooth level, not at participant level. However, adjusted RRs were presented at participant level

bobservational study downgraded one level for serious risk of bias due to confounding and missing data

conly male participants were included, which does not reflect the overall population. No direct causal effect of gender and second molar pathology is expected. Therefore, not downgraded for applicability

$d$ Participants enrolled in the study and returning for follow-up are likely to be more health aware than their age-matched peers in the community, and to practise better health behaviours. This would suggest more motivated participants in this study compared with the overall population. The presented significant effect may be greater in the overall population; however, we have not upgraded the quality of evidence for plausible confounding

eOwing to the wide $\mathrm{Cl}$, this outcome was downgraded one level for imprecision

${ }_{\mathrm{f}} \mathrm{RT}$ downgraded one level for risk of bias owing to 'some limitations' for multiple criteria (allocation concealment and incomplete outcome data), sufficient to lower confidence in the estimate of effect

gOwing to the small number of participants and the high rate of loss to follow-up, the quality of evidence was downgraded one level for imprecision 


\section{B A C K G R O U N D}

\section{Description of the condition}

Wisdom teeth, or third molars, generally erupt between the ages of 17 and 26 years (Venta 1999; Kruger 2001). More than other teeth, wisdom teeth can fail to erupt or can erupt only partially, with a worldwide impaction prevalence of $24 \%$ (Carter 2015). Impaction occurs when complete eruption into a normal functional position is prevented and completion of root growth is fully established. This can be due to lack of space (in the mouth), obstruction by another tooth or development in an abnormal position (Venta 1999). A tooth that is completely impacted can be entirely covered by soft tissue, covered partially by bone and soft tissue or completely covered by bone. Partial eruption occurs when the tooth is visible in the dental arch but has not erupted into a normal functional position (RCS England 1997). Impacted wisdom teeth have been associated with pathological changes such as pericoronitis, root resorption, periodontal disease, caries and development of cysts or tumours. An impacted wisdom tooth is called 'trouble-free' if the patient does not experience signs or symptoms of associated pain or discomfort (Song 1997). Other terms used in the literature include 'disease-free' and 'asymptomatic' (Dodson 2012).

The prevalence of asymptomatic disease-free impacted third molars varies widely and is influenced by age, sex and ethnicity (Bradley 1996). Impaction of wisdom teeth in the lower jaw is more common than in the upper jaw (Carter 2015; Celikoglu 2010). Most of the difficulties that follow surgical removal, such as postoperative morbidity, pain, discomfort and restricted activity, are related to lower wisdom teeth (Bienstock 2011).

When an impacted wisdom tooth cause pathological changes or pain, the tooth is no longer trouble-free. General agreement indicates that a wisdom tooth should be removed if pathology or symptoms are present. However, the management of asymptomatic disease-free wisdom teeth remains controversial (Kandasamy 2009).

\section{Description of the intervention}

Prophylactic removal of asymptomatic disease-free impacted wisdom teeth is defined as the surgical removal of wisdom teeth in the absence of symptoms and with no evidence of local disease. Many dentists and their patients believe that removal of asymptomatic disease-free wisdom teeth is justified to avoid future complications associated with these teeth. When surgical removal is carried out on older patients, the risk of postoperative complications is increased (Brokaw 1991; Chuang 2007; Mercier 1992; Tate 1994). An impacted wisdom tooth almost never has a functional role in the mouth and might increase risks of caries, periodontal disease and external root resorption associated with the adjacent second molar (Fisher 2012; Oenning 2015). Another argument often given for the removal of asymptomatic wisdom teeth is to prevent late lower incisor crowding.

Removal of impacted wisdom teeth is a common surgical procedure with significant associated costs (Renton 2012). Shortterm adverse effects of the removal of wisdom teeth include temporary nerve damage, alveolar osteitis (dry socket), infection, secondary haemorrhage, pain, swelling and trismus (restricted mouth opening). Long-term adverse effects of third molar surgery are uncommon but can include permanent nerve damage (in up to $1 \%$ of cases) and damage to adjacent teeth during surgery (Kandasamy 2009).

Retention of impacted wisdom teeth is defined as monitoring the status of wisdom teeth. To avoid adverse effects and the cost of removal of wisdom teeth, some advocate retention of asymptomatic disease-free impacted wisdom teeth (e.g. NICE 2000). This approach requires individuals to have regular dental reviews or 'checkups', so that the status of the wisdom teeth can be monitored.

\section{How the intervention might work}

In many countries, prophylactic removal of asymptomatic diseasefree wisdom teeth, whether impacted or fully erupted, was long considered as 'appropriate care' (Brokaw 1991; Tate 1994). Removal of wisdom teeth that may remain disease-free indefinitely is costly (Renton 2012) and can produce an unnecessary burden on healthcare resources (NICE 2000). With the introduction of National Institute for Health and Care Excellence (NICE) (NICE 2000) and Scottish Intercollegiate Guideline Network (SIGN) (SIGN 1999) clinical practice guidelines (CPGs) supporting conservative management of wisdom teeth, removal of wisdom teeth has declined in recent years (McArdle 2012). However, concerns include the possibility that retained wisdom teeth will increase the risk of pathology to surrounding structures in the long term, and that their removal at an older age may cause more frequent and severe complications (McArdle 2012; Renton 2012).

\section{Why it is important to do this review}

Cochrane Oral Health undertook an extensive prioritisation exercise in 2014 to identify a core portfolio of titles that were most important to maintain in The Cochrane Library (Worthington 2015). This review was identified as a priority title by the oral and maxillofacial surgery expert panel (Cochrane OHG priority review portfolio).

Wisdom tooth impaction is a common phenomenon (Carter 2015). Economic and personal costs are associated with removal of asymptomatic disease-free impacted wisdom teeth. Large variations have been noted in the management of asymptomatic disease-free impacted wisdom teeth (Knutsson 1992), but clinicians' decisions should be based on the best available research evidence, their clinical expertise and patient values (Bradley 1996).

\section{OB JECTIVES}

To evaluate the effects of removal compared with retention (conservative management) of asymptomatic disease-free impacted wisdom teeth in adolescents and adults.

\section{METHODS}

\section{Criteria for considering studies for this review Types of studies}

We considered randomised controlled trials (RCTs) for inclusion for all outcomes, with no restriction on their length of follow-up.

To assess long-term outcomes, we also considered quasi-RCTs and prospective cohort studies for inclusion only if outcomes were measured with follow-up of at least five years. We considered these non-randomised studies (NRSs) for inclusion in this review update, 
as long-term outcomes of retention/removal of asymptomatic disease-free impacted wisdom teeth are extremely unlikely to be studied in randomised trials.

\section{Types of participants}

Individuals (males and females of all ages) with asymptomatic disease-free impacted (maxillary or mandibular) wisdom teeth. An impacted tooth is defined as a tooth that has not erupted into a normal functional position. The tooth may be partially or completely covered by soft tissue and/or bone and might be visible, partially visible or invisible in the mouth.

\section{Types of interventions}

Studies comparing removal (or absence) with retention (or presence) of asymptomatic impacted wisdom teeth. The control group (retention or presence of asymptomatic disease-free impacted wisdom teeth) was likely to have continued to receive routine oral examinations and may have undergone wisdom tooth removal if symptoms or disease became evident.

\section{Types of outcome measures}

\section{Primary outcome}

Health-related quality of life measures associated with retention or removal of wisdom teeth (desirable and undesirable effects).

\section{Secondary outcomes}

Outcomes associated with retention of wisdom teeth (undesirable effects)

- Pericoronitis, infection and osteomyelitis

- Periodontitis (increased probing depths or alveolar bone loss affecting wisdom teeth or adjacent second molars)

- Caries (tooth decay affecting wisdom teeth or adjacent second molars (distal-cervical))

- Root resorption affecting wisdom teeth or adjacent second molars

- Dimensional changes in the dental arch (crowding)

- Cyst formation

- Tumour formation

- Inflammation/infection

\section{Outcomes associated with removal of wisdom teeth (undesirable} effects)

- Alveolar osteitis, postoperative infection and osteomyelitis

- Nerve injury (lingual nerve and inferior alveolar nerve)

- Damage to adjacent teeth during surgery

- Bleeding

- Osteonecrosis related to medication/radiotherapy

- Inflammation/infection

Costs

- Days off work/study

- Direct costs associated with retention or removal of wisdom teeth and treatment of associated symptoms or complications

\section{Search methods for identification of studies}

The Information Specialist for Cochrane Oral Health conducted systematic searches for RCTs and controlled clinical trials. The subject strategies for databases were modelled on the search strategy designed for MEDLINE Ovid.

\section{Electronic searches}

We searched the following databases:

- Cochrane Oral Health's Trials Register (searched 24 May 2016) (Appendix 1);

- Cochrane Central Register of Controlled Trials (CENTRAL; 2016, Issue 4) in the Cochrane Library (searched 24 May 2016) (Appendix 2);

- MEDLINE Ovid (1946 to 24 May 2016) (Appendix 3);

- Embase Ovid (1980 to 24 May 2016) (Appendix 4).

We placed no restrictions on language or date of publication when searching electronic databases.

\section{Searching other resources}

We searched the following trials registries:

- US National Institutes of Health Ongoing Trials Register ClinicalTrials.gov (http://clinicaltrials.gov/; searched 24 May 2016); (Appendix 5);

- World Health Organization International Clinical Trials Registry Platform (apps.who.int/trialsearch; searched 24 May 2016) (Appendix 6).

We did not perform a separate search for adverse effects of interventions; we considered these in included studies only.

\section{Data collection and analysis}

\section{Selection of studies}

Eight review authors (Hossein Ghaeminia (HG), John Perry (JP), Marloes Nienhuijs (MN), Verena Toedling (VT), Marcia Tummers (MT), Theo Hoppenreijs (TH), Wil van der Sanden (WvdS) and Dirk Mettes (DM)), in duplicate, independently and not blinded, assessed the titles, keywords, abstracts and/or methods sections of studies identified by the search strategy. We obtained relevant articles identified by reference searching as well as full-text articles selected by the review authors. We read in full the articles on which review authors disagreed and made the decision to include or exclude upon discussion. Eligibility criteria were:

- studies comparing the removal (or absence) with retention (or presence) of (maxillary or mandibular) asymptomatic diseasefree impacted wisdom teeth;

- studies providing data on at least one of the selected primary or secondary outcomes;

- studies reporting quantitative outcomes; and

- studies with a suitably matched control or comparison group.

\section{Data extraction and management}

Five review authors (HG, JP, VT, MT and DM) extracted relevant data from the included studies independently and in duplicate. We recorded the following types of data: study design, risk of bias, studied outcome measures, year of publication, duration of follow-up, sample size, number and characteristics of participants in each group and reported results. We assessed the comparability of participant characteristics at baseline, how researchers dealt with confounding, eligibility criteria and the methodology used in

Surgical removal versus retention for the management of asymptomatic disease-free impacted wisdom teeth (Review) 
measuring outcomes. We discussed the results until we reached agreement. In cases of uncertainty, we contacted study authors for clarification. Should uncertainty persist, we did not use the data.

\section{Assessment of risk of bias in included studies}

All review authors assessed risk of bias of included studies independently and in duplicate. We resolved disagreements by discussion.

\section{Randomised controlled trials (RCTs)}

We used the tool of The Cochrane Collaboration for assessing risk of bias along with a 'risk of bias' table to assess each study, as outlined in Chapter 8 of the Cochrane Handbook for Systematic Reviews of Interventions version 5.1.0 (Higgins 2011).

We assessed several domains as having 'low risk' of bias, 'high risk' of bias or 'unclear risk' of bias, including:

- random sequence generation (selection bias);

- allocation concealment (selection bias);

- blinding of outcome assessment (detection bias);

- incomplete outcome data (attrition bias);

- selective outcome reporting (reporting bias); and

- other bias.

We further assessed the randomisation procedure, sample size calculation, definitions of eligibility criteria, definitions of success criteria and comparability of control and treatment groups at the start of the trial. We contacted study authors to seek clarification when data were uncertain. We reported these assessments for each individual study in the 'Risk of bias' table and under Characteristics of included studies.

We performed an overall assessment of risk of bias for primary and secondary outcomes (across domains) across RCTs (Higgins 2011). Within a study, we assigned a summary assessment of low risk of bias when risk of bias was low for all key domains, unclear risk of bias when risk of bias was unclear for one or more key domains and high risk of bias when risk of bias was high for one or more key domains. Across studies, we rated a summary assessment as having low risk of bias when we derived most information from studies at low risk of bias, unclear risk of bias when we obtained most information from studies at low or unclear risk of bias and high risk of bias when we gathered most information from studies with risk of bias high enough to affect interpretation of results.

\section{Non-randomised studies (NRSs)}

We used the Cochrane Risk of Bias Assessment Tool for NonRandomized Studies of Interventions (ACROBAT-NRSI) when assessing risk of bias of NRSs (Sterne 2014).

We assessed various domains for each primary or secondary outcome as 'low risk' of bias, 'moderate' risk of bias, 'serious' risk of bias, 'critical' risk of bias or 'no information', including:

- bias due to confounding;

- bias in selection of participants into the study;

- bias in measurement of interventions;

- bias due to departure from intended interventions;

- bias due to missing data;
- bias in measurement of outcomes; and

- bias in selection of the reported result.

\section{Control for confounding}

We prespecified age, oral and general health status as critically important confounding domains.

We assessed which of these confounding domains had an impact on the specific outcome, and whether they were balanced at baseline or at outcome assessment in studies where participants were allocated to groups on the basis of their outcome. We also assessed whether the confounding domains were balanced between groups or at the design stage through matching when participants were allocated to groups or through statistical adjustments at the analysis stage.

Oral health status included the frequency of routine dental checkups, the DMFS/T (Decayed Missing Filled Surfaces/Teeth) index, frequency of oral hygiene and carbohydrate intake from which at least one of these variables required to be balanced or adjusted for.

No critically important co-interventions were expected to influence the long-term outcomes.

We undertook risk of bias assessment for each primary and secondary outcome (across domains) within each non-randomised study (Sterne 2014). Within a study for each outcome, we assigned low risk of bias when risk of bias for all key domains was low, moderate risk of bias when risk of bias for one or more key domains was moderate, serious risk of bias when risk of bias for one or more domains was serious, critical risk of bias when risk of bias for one or more key domains was critical and 'no information' when no clear indication suggested that the outcome was at serious or critical risk of bias and information was insufficient in one or more key domains of bias. We considered certain risks of bias to be additive, so that certain risks of bias in multiple domains led to an overall judgement of greater risk of bias.

\section{Measures of treatment effect}

For RCTs and prospective studies with dichotomous outcomes, we expressed the estimates of treatment effects of an intervention as risk ratios (RRs) (outcome present or absent) together with $95 \%$ confidence intervals (Cls). For continuous outcomes, we used mean differences (MDs) and standard deviations (SDs).

\section{Unit of analysis issues}

We assessed the carry-over effect for all split-mouth studies. If a split-mouth design was deemed inappropriate for investigating the outcome or outcomes assessed in a particular study, we excluded the study. If we had included split-mouth studies, we intended to approximate a paired analysis, as recommended by the Cochrane Handbook for Systematic Reviews of Interventions (Higgins 2011). In the case of an ideal study (i.e. one that reported means and SDs for both groups, and MDs and SDs/standard errors (SEs) between two groups), we intended to calculate intragroup correlation coefficients (ICCS); if we identified more than one ideal study, we intended to calculate the mean ICC, which we would have adopted in calculating the MD and SD/SE for other, similar split-mouth studies. If no ideal study was identified, then we assumed that the ICC was 0.5 . 
For clustered data, in trials where the unit of analysis was the tooth, and the number of teeth included in the trial was not more than twice the number of participants, we treated the data as if the unit of analysis was the individual. We recognised that the $95 \%$ confidence intervals produced would appear narrower (i.e. the estimate would seem to be more precise) than they should have been, and we therefore interpreted these accordingly.

\section{Dealing with missing data}

We assessed incomplete data during the risk of bias assessment. If data were absent, we recorded the presence of reporting bias. We captured missing data on the data extraction form and reported them in the risk of bias tables. We contacted study authors to try to acquire missing data for inclusion.

\section{Assessment of heterogeneity}

We would have carried out assessment of heterogeneity in quantifying inconsistency across studies by using the 12 statistic, as described in Section 9.5.2 of the Cochrane Handbook for Systematic Reviews of Interventions.

\section{Assessment of reporting biases}

We assessed reporting bias as between-study publication bias or within-study reporting bias. We assessed within-study reporting bias by comparing outcomes reported in the published report against the study protocol, whenever this could be obtained. If we could not obtain the protocol,we compared outcomes listed in the methods section with those whose results were reported. If non-significant results were mentioned but were not reported adequately, we considered that bias was likely to occur in a metaanalysis, and we sought further information from the authors of study reports. Otherwise, we noted this meta-analysis as having high risk of bias. If information was insufficient to judge the risk of bias, we noted this meta-analysis as having unclear risk of bias. If any meta-analysis had included a sufficient number of trials (more than 10), we would have assessed publication bias according to the recommendations on testing for funnel plot asymmetry, as described in Section 10.4 of the Cochrane Handbook for Systematic Reviews of Interventions (Higgins 2011). If asymmetry had been identified, we would have examined possible causes or assessed the asymmetry by using a table to list the outcomes reported by each study included in the review, to identify whether any studies did not report outcomes that had been reported by most studies.

\section{Data synthesis}

For RCTs, we planned to conduct a meta-analysis if sufficient studies reported the same outcome measure. We planned to combine risk ratios and calculate $95 \%$ confidence intervals for dichotomous data, and to combine mean differences with $95 \%$ confidence intervals for continuous data. We planned to use the fixed-effect model unless more than three studies were included in each meta-analysis, or if clinical heterogeneity among studies existed, in which case we would have used the random-effects model.
Given that data from NRSs are prone to bias and are often heterogeneous, we would have carried out separate meta-analyses for NRSs and presented results according to different study designs and outcomes. For NRSs, we would not have performed a meta-analysis in cases of severe methodological and clinical heterogeneity, or when we found too few NRSs. In this instance, we would group the studies by outcome and present results as a narrative summary in the text, as well as in tables and in the form of a forest plot without an overall summary statistic.

We would not have included in any analyses data from NRSs with a critical risk of bias.

\section{Subgroup analysis and investigation of heterogeneity}

Owing to lack of data, we did not perform a subgroup analysis. If sufficient data had been present, we would have performed a subgroup analysis for participant age (younger than 18 years, 18 to 25 years, 26 to 30 years, over 30 years).

\section{Sensitivity analysis}

For any pooled analyses, we planned to undertake sensitivity analyses to examine the effects of randomisation, allocation concealment and blinded outcome assessment on overall estimates of effect.

For meta-analyses of NRSs, we planned to undertake sensitivity analyses after removing NRSs that had not adequately adjusted for significant differences in confounding domains.

\section{Presentation of main results}

We prepared a 'Summary of findings' table (SoF) for the primary and secondary outcomes of this review using GRADE (Grading of Recommendation, Assessment, Development and Evaluation Working Group) profiler software. We assessed the overall quality of the evidence, using GRADE criteria, as high, moderate, low or very low (Higgins 2011). GRADE guidance states that RCTs are considered to present high quality evidence and are downgraded as necessary on the basis of overall risk of bias of included studies, directness of the evidence, consistency of the results, precision of the estimates, risk of publication bias and magnitude of effect. Sound observational studies are considered to present low quality evidence but can be upgraded if a large effect size is reported with no obvious bias to explain that effect.

\section{RES U LTS}

\section{Description of studies}

\section{Results of the search}

After performing the search up to 24 May 2016, we retrieved a total of 3696 references; this resulted in 2472 records after deduplication. We found no additional studies or ongoing studies after searching the trial registers. After screening the titles and abstracts of these references, we selected 25 articles. Finally, we excluded 23 articles and included two.

See Figure 1 for a study flow diagram of the search update. 
Figure 1. Study selection flow diagram

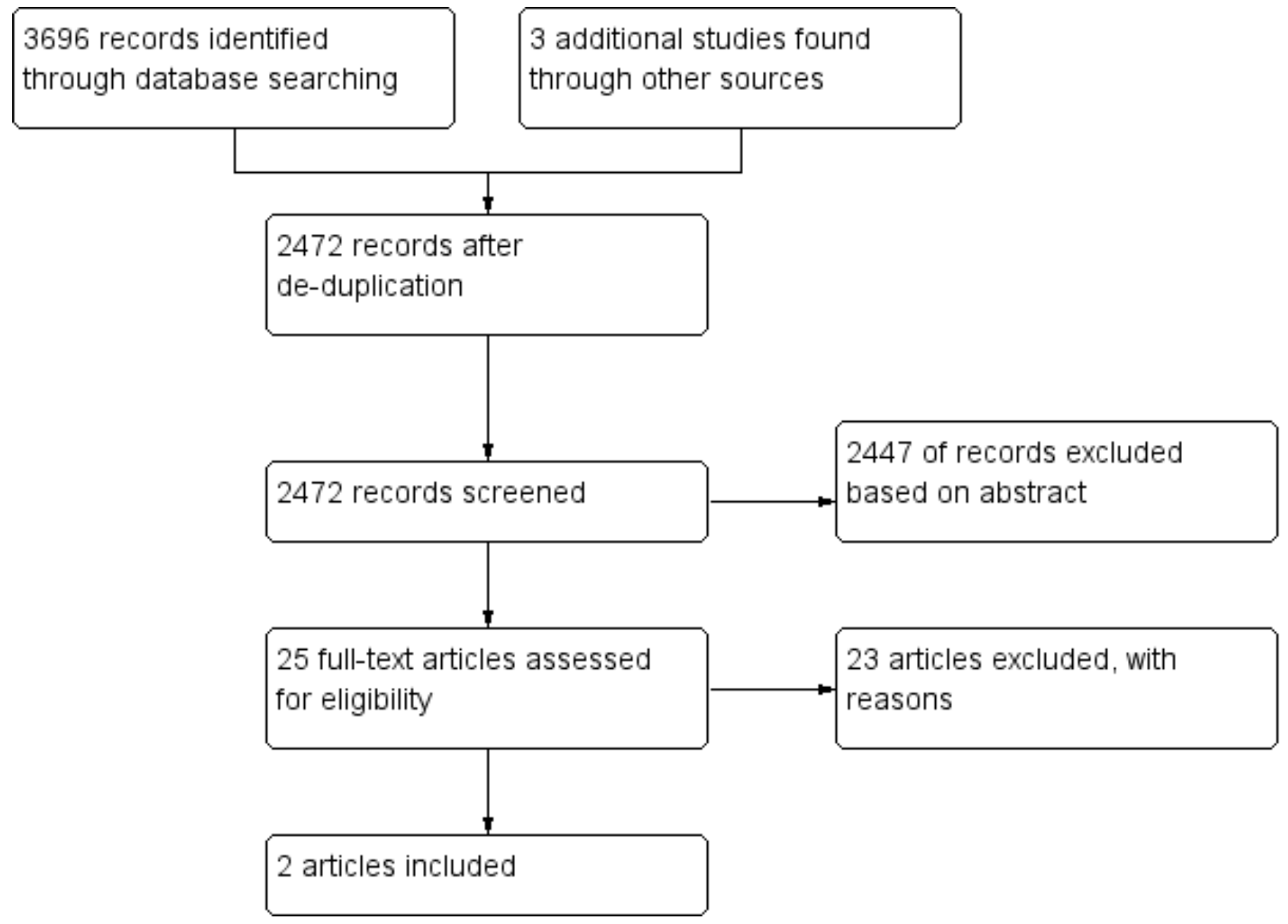

\section{Included studies}

The last published version of this review included one RCT (Harradine 1998), which compared surgical removal with retention of asymptomatic disease-free impacted wisdom teeth in adolescent participants who had previously undergone orthodontic treatment. We assessed this study including 164 participants to be at overall high risk of bias. In the present update, we added one prospective cohort study and have included a total of two studies with 1395 participants (493 analysed participants). We have provided summary details in the Characteristics of included studies table.

\section{Characteristics of the study settings}

We included in this review two studies involving data from 493 analysed participants: one RCT with a parallel-group design conducted in a dental hospital setting in the United Kingdom (Harradine 1998), and one prospective cohort study conducted in the private sector in the USA (Nunn 2013).

\section{Characteristics of participants}

The RCT (Harradine 1998) recruited 164 adolescents (55\% female) who had previously undergone orthodontic treatment and had 'crowded' wisdom teeth, in which the long axis and the presumed path of eruption of the wisdom teeth was through the adjacent second molar.
The prospective cohort study (Nunn 2013) recruited 1231 healthy male volunteers, aged 24 to 84 years, who had both first and second molars present in at least one quadrant at baseline and had undergone at least one follow-up examination (at three years). Wisdom teeth at baseline were categorised as absent (previous removal or agenesis), erupted, 'soft tissue' impacted or 'bony' impacted.

\section{Characteristics of the interventions}

The RCT (Harradine 1998) compared surgical removal with retention of asymptomatic disease-free impacted wisdom teeth.

The prospective cohort study (Nunn 2013) compared retention with absence (previous removal or agenesis) of asymptomatic diseasefree impacted wisdom teeth.

\section{Characteristics of the outcome measures}

The RCT (Harradine 1998) measured the secondary outcome dimensional changes in the dental arch - at baseline and five years later. Study authors assessed three measures of dimensional change in the dental arch (Little's irregularity index, intercanine width and arch length) using digitised study models.

The prospective cohort study (Nunn 2013) measured secondary outcomes - periodontitis and caries associated with the distal of the adjacent second molar - during a follow-up period of between three and over 25 years. Probing depths greater than 4 
$\mathrm{mm}$ associated with the distal of the adjacent second molar were assessed clinically, and a trained, calibrated periodontist assessed alveolar bone loss and caries associated with the distal of the adjacent second molar, both clinically and radiographically.

\section{Excluded studies}

We have provided summary details in the Characteristics of excluded studies table. After screening the full text of the identified NRSs, we excluded 23 studies because:

- three studies had follow-up less than five years (Blakey 2009; Coleman 2011; Huang 2014);

- six studies used an inappropriate study design (Ades 1990; Lindqvist 1982; Moss 2007; Moss 2007a; Offenbacher 2012; Rahman 2009; Venta 1993a);

- seven studies did not have a suitably matched control or comparison group (Dicus 2010; Fisher 2012; Fisher 2013; Garaas 2012; Golden 2015; Haug 2005; Venta 2015); and

- six studies included an inappropriate study population (DicusBrookes 2013; Moss 2009; Moss 2013; Moss 2013a; Nemcovsky 1997; Venta 1993).

\section{Risk of bias in included studies}

We have reported risk of bias separately for the RCT and the prospective cohort study. See Characteristics of included studies and Table 1.

The RCT (Harradine 1998) had adequate sequence generation. Study authors did not explicitly describe the method of allocation concealment, and this gave rise to high risk of selection bias. It was impossible for participants and operators to be blinded to the intervention, but the outcome assessor was blinded. We assessed risk of performance and detection bias to be low. Fifty-three per cent of the original participants $(\mathrm{N}=87$ ) were lost to follow-up at five years. More participants were lost from the retention group $(49 / 82=60 \%)$ than from the removal group $(38 / 82=46 \%)$, and study authors were unable to contact these participants. study authors provided no data on the gender balance between groups of those who completed the study compared with those who did not. We assessed this trial to be at high risk of attrition bias, which could have affected overall results. We assessed risk of bias due to selective reporting as unclear. We could identify no other major potential sources of bias. We considered this RCT to be at high risk of bias overall.

We assessed the prospective cohort study (Nunn 2013) to be at serious risk of bias owing to confounding and missing data. Study authors adjusted analyses for baseline age, smoking status, education and baseline second molar measures but did not measure oral health status. These factors may contribute to the development of second molar pathology; therefore this study is at serious risk of bias owing to confounding. In the first Dental Longitudinal Study, beginning in 1969, 1231 volunteers were enrolled (Kapur 1972). Eventually only 416 met the inclusion criteria and were analysed. Data regarding the excluded participants are missing. Participants with pathology associated with their wisdom teeth are likely to have had them removed before the study was initiated; therefore, this study is at serious risk of bias owing to missing data. We assessed this study to be at low risk of bias in measurement of interventions and outcomes. We assessed risk of bias due to selection of participants into the study, departures from intended interventions and selection of reported results as moderate. We considered this prospective cohort study overall to be at serious risk of bias for all assessed outcomes. See Table 1.

\section{Effects of interventions}

See: Summary of findings for the main comparison

\section{Primary outcome - health-related quality of life}

Neither of the two included studies investigated health-related quality of life measures associated with retention or removal of asymptomatic disease-free impacted wisdom teeth.

\section{Secondary outcomes - outcomes associated with retention of wisdom teeth (undesirable effects)}

\section{Periodontitis (increased probing depths or alveolar bone loss affecting wisdom teeth or adjacent second molars)}

The prospective cohort study (Nunn 2013) with 416 analysed participants (with 804 wisdom teeth) reported relative risks for probing depths greater than $4 \mathrm{~mm}$ and alveolar bone loss associated with the distal of the adjacent second molar in the absence compared with the presence of asymptomatic disease-free impacted wisdom teeth. 'Soft tissue' and 'bony' impactions were calculated at the participant level.

In the absence of wisdom teeth, the risk of probing depths greater than $4 \mathrm{~mm}$ associated with the distal of the adjacent second molar was significantly less than if soft tissue impacted wisdom teeth were present (RR $0.15,95 \% \mathrm{Cl} 0.07$ to 0.34 ) (very low quality evidence). There was no statistically significant difference in the risk of probing depths greater than $4 \mathrm{~mm}$ associated with the distal of the adjacent second molar in the absence compared with the presence of bony impacted wisdom teeth (RR $0.63,95 \% \mathrm{Cl} 0.37$ to 1.04) (very low quality evidence).

In the absence of wisdom teeth, the risk of alveolar bone loss associated with the distal of the adjacent second molar was significantly less than if soft tissue (RR $0.11,95 \% \mathrm{Cl} 0.06$ to 0.22 ) or bony impacted wisdom teeth ( $\mathrm{RR} 0.32,95 \% \mathrm{Cl} 0.19$ to 0.54 ) were present (very low quality evidence).

\section{Caries (tooth decay affecting wisdom teeth or adjacent second molars (distal-cervical))}

The prospective cohort study (Nunn 2013) with 416 analysed participants (with 804 wisdom teeth) reported relative risks for caries associated with the distal of the adjacent second molar in the absence compared with retention of asymptomatic diseasefree impacted wisdom teeth. 'Soft tissue' and 'bony' impactions were calculated at the participant level.

There was no statistically significant difference in the prevalence of distal caries associated with the adjacent second molar in the absence compared with the presence of bony impacted wisdom teeth (RR $0.69,95 \% \mathrm{Cl} 0.27$ to 1.82 ) and soft tissue impacted wisdom teeth (RR $1.20,95 \% \mathrm{Cl} 0.17$ to 9.10 ) (very low quality evidence).

\section{Dimensional changes in the dental arch (crowding)}

The RCT (Harradine 1998) with 77 analysed participants reported mean differences with 95\% confidence intervals for dimensional changes in the dental arch for surgical removal compared with retention of asymptomatic disease-free impacted wisdom teeth. 
There were no statistically significant differences between groups for the outcomes of Little's irregularity index (MD - $0.3 \mathrm{~mm}, 95 \%$ $\mathrm{Cl}-1.3$ to 0.7 ) and intercanine width (MD $-0.01 \mathrm{~mm}, 95 \% \mathrm{Cl}-0.37$ to 0.35 ) (low quality evidence). There was a small but statistically significant difference between groups in arch length (MD $-1.03 \mathrm{~mm}$, $95 \% \mathrm{Cl}-0.56$ to $-1.50, \mathrm{P}$ value $=0.0001)$, but this difference is unlikely to be clinically significant (low quality evidence). These findings appear to be inconsistent with each other but may be explained, as the study authors' note, by persistent residual premolar extraction space in some participants at study entry.

\section{Other outcomes associated with retention}

No included studies reported pericoronitis, root resorption, cyst formation, tumour formation or inflammation/infection.

\section{Outcomes associated with removal of wisdom teeth (undesirable effects)}

No included studies measured outcomes or adverse events associated with removal of asymptomatic disease-free impacted wisdom teeth (alveolar osteitis/postoperative infection, nerve injury, damage to adjacent teeth during surgery, bleeding, osteonecrosis related to medication/radiotherapy, inflammation/ infection).

\section{Costs}

The included studies did not measure days off work/study or direct costs associated with retention or removal of wisdom teeth and treatment of associated symptoms or complications.

\section{DISCUSSION}

\section{Summary of main results}

No eligible studies in this review reported the effects of removal compared with retention of asymptomatic disease-free impacted wisdom teeth for the primary outcome measure: health-related quality of life.

Studies have provided only low or very low quality evidence of the effects of removal compared with retention of asymptomatic disease-free impacted wisdom teeth for a limited number of secondary outcome measures. Very low quality evidence from one prospective cohort study suggests that the presence of asymptomatic disease-free impacted wisdom teeth may be associated with increased risk of periodontitis associated with the adjacent second molar in the long term. The same study provided no evidence to suggest that the presence of impacted wisdom teeth changes the risk of caries affecting the adjacent second molar. Low quality evidence from a single randomised controlled trial (RCT) included in this review found no evidence to suggest that removal of asymptomatic disease-free impacted wisdom teeth has a clinically significant effect on dimensional changes in the dental arch.

No included studies have reported other outcomes or adverse events associated with removal (alveolar osteitis/ postoperative infection, nerve injury, damage to adjacent teeth during surgery, bleeding, osteonecrosis related to medication/ radiotherapy, inflammation/infection) or retention (pericoronitis, root resorption, cyst formation, tumour formation, inflammation/ infection) of asymptomatic disease-free impacted wisdom teeth.

\section{Overall completeness and applicability of evidence}

Substantial differences are evident between participants in the two included studies, and these participants are not representative of the general population with asymptomatic disease-free impacted wisdom teeth.

The included RCT focused only on adolescent patients who had completed orthodontic treatment. Loss to follow-up was a major obstacle in obtaining data about the effects of extraction of asymptomatic disease-free impacted wisdom teeth, as participants are likely to be recruited towards the end of their high school years and are difficult to follow up as they move to higher education, go travelling or change locations when seeking employment.

The prospective cohort study included only male participants aged 24 to 84 years from a single geographic area who were self selected volunteers. Participants enrolled in the study who returned for follow-up are likely to be more health aware than their agematched peers in the community and to practise better health behaviours. This would suggest that participants in this study were more motivated than the overall population. Retained wisdom teeth in this group of participants were associated with increased risk of periodontal disease affecting the adjacent second molar. Risk of damage to the second molar might be even greater in populations with poor oral health. If wisdom teeth or adjacent second molars need to be removed at an older age owing to disease, the personal and financial costs may be greater than at a young age. However, included studies have provided no information on quality of life measures and costs.

Included studies have provided no information regarding other adverse effects of removal (alveolar osteitis/postoperative infection, nerve injury, damage to adjacent teeth during surgery, bleeding, osteonecrosis related to medication/ radiotherapy, inflammation/infection) or retention (pericoronitis, root resorption, cyst formation, tumour formation, inflammation/ infection) of asymptomatic disease-free impacted wisdom teeth.

We chose the primary outcome of health-related quality of life to capture the benefits and harms associated with removal and retention of asymptomatic disease-free impacted wisdom teeth. We chose this outcome measure because of the difficulties of comparing various outcomes (e.g. rate of complications after surgical removal, incidence of pathological change in cases of retention, rate of complications due to delayed surgical removal) (Song 2000). Unfortunately, the included studies did not assess this primary outcome. The Oral Health Impact Profile is a valid and reliable measure of oral health-related quality of life in general dental practice and is responsive to impacted third molar clinical change (Fernandes 2006). It is suitable for measuring the effects of removal or retention of asymptomatic disease-free impacted wisdom teeth on oral health-related quality of life in future studies.

\section{Quality of the evidence}

The single RCT included in this review provided low quality evidence of the effects of surgical removal of asymptomatic disease-free impacted wisdom teeth on dimensional changes in the dental arch at five years' follow-up. We considered this trial to be at high risk of bias overall owing to limitations of allocation concealment and incomplete outcome data sufficient to lower confidence in the estimate of effect. In addition, the small number 
of participants and the high rate of loss of participants to follow-up led to imprecision in the estimate of effect.

As RCTs investigating longer-term and rare effects of removal or retention of asymptomatic disease-free impacted wisdom teeth are unlikely to be feasible, we considered non-randomised studies (NRSs) for inclusion in this review update. A high quality prospective cohort study might be a more suitable design for evaluating the outcomes of retained wisdom teeth. However, NRSs are likely to be at higher risk of bias compared with RCTs. With the introduction of the Cochrane Risk of Bias Tool for NRSs (ACROBATNRSI, Sterne 2014), it is possible to assess the risk of bias in NRSs more systematically. (The tool was updated in 2016 and is now called ROBINS-I).

We assessed the included prospective cohort study, Nunn 2013, to be at serious risk of bias because of confounding. Study authors adjusted the analyses for baseline age, smoking status, education and baseline second molar measures but did not measure oral health status. Oral health status may contribute to the development of pathology associated with wisdom teeth and adjacent second molars. A recent study that measured the frequency of dental checkups reported no effects of wisdom tooth removal on the incidence of pathology associated with the second molar (Huang 2014). However, this study provided only two years of follow-up and was not eligible for inclusion in this review. As pathology may develop in a wisdom tooth or in the adjacent second molar over the whole of a person's lifetime, studies with long-term follow-up are needed.

The quality of evidence available from the two studies included in this review is of low to very low quality, so we cannot rely on these findings to support clinical practice.

\section{Agreements and disagreements with other studies or reviews}

Despite the lack of evidence, clinical practice guidelines (CPGs) on the management of impacted wisdom teeth have been available for 15 years. The Scottish Intercollegiate Guideline Network (SIGN 1999) published a CPG for the management of unerupted and impacted wisdom teeth in 1999, and the National Institute for Health and Care Excellence (NICE 2000) in the UK published a CPG for removal of wisdom teeth in 2000. Both concluded that in light of the costs and risks associated with removal, no valid evidence supports the prophylactic removal of asymptomatic disease-free wisdom teeth. In 2000, the number of patients requiring surgical removal of wisdom teeth in secondary care dropped by $30 \%$ (McArdle 2012). However, since 2003, an increase in the removal of wisdom teeth has been registered, with equal numbers of patients requiring wisdom tooth removal in 2000 and 2010. In addition, the mean age of patients requiring removal of wisdom teeth has increased from 25 years before the introduction of the NICE CPD to 32 years in 2010 (McArdle 2012). The review authors suggest that implementation of CPGs has not resulted in a reduction in the number of wisdom teeth removed but has increased the number of wisdom teeth requiring removal at an older age owing to caries (McArdle 2012; Renton 2012). However, risk of bias is high in all domains in this study owing to the use of hospital coding systems. The prospective cohort study included in this review (Nunn 2013) found increased risk of distal caries for second molars adjacent to fully erupted wisdom teeth, but not for impacted wisdom teeth.
In the late 1990s, the American Association of Oral and Maxillofacial Surgeons acknowledged the absence of evidence to guide clinical decision making for the management of asymptomatic diseasefree impacted wisdom teeth, and allocated a significant amount of money for a multi-centre study (Kandasamy 2009). More than 70 papers have been published as a result of this study, including a large cohort study that documents the incidence of adverse effects following more than 8000 third molar extractions in patients 25 years of age or older (Haug 2005). Large studies have documented the incidence of complications associated with retention of asymptomatic disease-free wisdom teeth. Most of these studies did not focus on asymptomatic disease-free impacted wisdom teeth but investigated the occurrence of pathology associated with 'visible teeth'. This resulted in serious risk of selection bias in all of these studies; therefore we did not include them in this review. The American Association of Oral and Maxillofacial Surgeons "leans more towards the removal of asymptomatic disease-free third molars on the basis they are associated with increased periodontal probing depths and are therefore a potential source of chronic inflammation" (Kandasamy 2009). However, it should be questioned whether only pocket depths are indicative of periodontal pathology. A 4-mm pocket depth in the second molar may be influenced by the eruption status of the third molar, without inflammation or other pathology. The prospective cohort study included in this review (Nunn 2013) found increased risk of second molar periodontal pathology adjacent to impacted third molars when distal alveolar bone loss was assessed radiographically in addition to distal probing depths.

Disagreement regarding the removal of asymptomatic diseasefree impacted wisdom teeth is ongoing (Huang 2014), and the key question remains: why should impacted wisdom teeth be removed in the absence of symptoms or pathological conditions? Unfortunately, reliable estimates of the onset of pathology related to retained impacted wisdom teeth are unavailable (Venta 2004), in large part because of the widespread practice of routine removal over past decades. Recently, cross-sectional studies performed in elderly individuals in the USA (Fisher 2010) and Finland (Venta 2015) have reported that most wisdom teeth are removed over a lifetime, and that up to $80 \%$ of surviving wisdom teeth have associated pathology such as caries or periodontitis in patients over the age of 74 years. The incidence of severe pathology associated with wisdom teeth, such as cysts and tumours, is low $(<2 \%)$. Evidence from these cross-sectional studies is very unreliable, and studies assessing the outcomes of retained wisdom teeth are rare because of problems associated with a complex long-term prospective study design (Van der Sanden 2002). Studies have shown that distally impacted lower wisdom teeth and partially erupted wisdom teeth are more likely to become symptomatic (Venta 1993a). Actuarial lifetime tables have shed some light on the natural history of asymptomatic impacted lower wisdom teeth, but longer follow-up periods are required (Fernandes 2010).

The decision about whether to recommend removal or retention of asymptomatic disease-free wisdom teeth may be influenced by cost (whether publicly funded, covered through insurance or borne by the patient) and by professional liability. Patient values and preferences should play a more prominent role in deciding whether asymptomatic disease-free impacted wisdom teeth should be removed. 


\section{AUTHORS' CONCLUSIONS}

\section{Implications for practice}

Insufficient evidence is available to support the surgical removal or retention of asymptomatic disease-free impacted wisdom teeth. Although some evidence suggests that retaining asymptomatic disease-free impacted wisdom teeth may increase the risk of periodontitis associated with adjacent second molars in the long term, this evidence is of very low quality. In light of the lack of available evidence, patient values should be considered and clinical expertise used to guide shared decision making with patients who have asymptomatic disease-free impacted wisdom teeth. If the decision is made to retain asymptomatic disease-free impacted wisdom teeth, clinical assessment at regular intervals to prevent undesirable outcomes is advisable.

\section{Implications for research}

Long-term, well-designed prospective studies comparing removal or retention of asymptomatic disease-free impacted wisdom teeth are urgently needed. Well-designed RCTs investigating the longterm and rare effects of retention and removal of asymptomatic disease-free impacted wisdom teeth, in a representative group of individuals, are unlikely to be feasible. If randomisation is not possible, studies should register important baseline data such as age and general and oral health status, including the frequency of dental checkups, the DMFS/T (Decayed Missing Filled Surfaces/ Teeth) index or frequency of oral hygiene. These confounding domains should be balanced at baseline or adjusted for with appropriate analyses. A crucial and easily comparable outcome is oral health-related quality of life. However, further development and validation of patient-reported outcome measures (PROMs) are needed in the context of managing asymptomatic disease-free impacted wisdom teeth. The secondary outcomes described in this review are also of great importance for decision making in the management of asymptomatic disease-free impacted wisdom teeth and should be measured in future studies. Because pathology may develop in a wisdom tooth or in the adjacent second molar over the whole of a patient's lifetime, studies with long-term followup (at least five years) are needed. This is very challenging, as young participants are difficult to contact when they move to higher education, travel or change locations while seeking employment.

\section{ACKNOWLEDGEMENTS}

We would like to thank Anne Littlewood at Cochrane Oral Health for her guidance and coaching in searching the literature, Philip Riley and Laura MacDonald for their support at the editorial base of Cochrane Oral Health and Richard Grol and Alphons Plasschaert for initiating this review. We also would like to thank referees Scott $L$. Tomar, Tara Renton, Eleni Besi and Julian Yates for their feedback. We thank Dolores P Matthews for copy editing. 


\section{RE F E R E N C E S}

\section{References to studies included in this review}

Harradine 1998 \{published data only\}

Harradine NW, Pearson MH, Toth B. The effect of extraction of third molars on late lower incisor crowding: a randomized controlled trial. British Journal of Orthodontics 1998;25(2):117-22.

\section{Nunn 2013 \{published data only\}}

Nunn ME, Fish MD, Garcia RI, Kaye EK, Figuerosa R, Gohel A, et al. Retained asymptomatic third molars and risk for second molar pathology. Journal of Dental Research 2013;92(12):1095-9.

\section{References to studies excluded from this review}

Ades 1990 \{published data only\}

Ades AG, Joondeph DR, Little RM, Chapko MK. A long-term study of the relationship of $3 \mathrm{rd}$ molars to changes in the mandibular dental arch. American Journal of Orthodontics and Dentofacial Orthopedics 1990;97(4):323-35.

Blakey 2009 \{published data only\}

Blakey GH, Parker DW, Hull DJ, White RP Jr, Offenbacher S, Phillips C, et al. Impact of removal of asymptomatic third molars on periodontal pathology. Journal of Oral and Maxillofacial Surgery 2009;67(2):245-50.

\section{Coleman 2011 \{published data only\}}

Coleman M, McCormick A, Laskin DM. The incidence of periodontal defects distal to the maxillary second molar after impacted third molar extraction. Journal of Oral and Maxillofacial Surgery 2011;69(2):319-21.

\section{Dicus 2010 \{published data only\}}

Dicus C, Blakey GH, Faulk-Eggleston J, Hoverstad E, Offenbacher S, Phillips $\mathrm{C}$, et al. Second molar periodontal inflammatory disease after third molar removal in young adults. Journal of Oral and Maxillofacial Surgery 2010;68(12):3000-6.

\section{Dicus-Brookes 2013 \{published data only\}}

Dicus-Brookes C, Partrick M, Blakey GH, Faulk-Eggleston J, Offenbacher S, Phillips C, et al. Removal of symptomatic third molars may improve periodontal status of remaining dentition. Journal of Oral and Maxillofacial Surgery 2013;71(10):1639-46.

Fisher 2012 \{published data only\}

Fisher EL, Garaas R, Blakey GH, Offenbacher S, Shugars DA, Phillips $\mathrm{C}$, et al. Changes over time in the prevalence of caries experience or periodontal pathology on third molars in young adults. Journal of Oral and Maxillofacial Surgery 2012;70(5):1016-22.

\section{Fisher 2013 \{published data only\}}

Fisher EL, Blakey GH, Offenbacher S, Phillips C, White RP Jr. Mechanical debridement of subgingival biofilm in participants with asymptomatic third molars does not reduce deeper probing depths in the molar regions of the mouth. Journal of Oral and Maxillofacial Surgery 2013;71(3):467-74.
Garaas 2012 \{published data only\}

Garaas RN, Fisher EL, Wilson GH, Phillips C, Shugars DA, Blakey $\mathrm{GH}$, et al. Prevalence of third molars with caries experience or periodontal pathology in young adults. Journal of Oral and Maxillofacial Surgery 2012;70(3):507-13.

Golden 2015 \{published data only\}

Golden BA, Baldwin C, Sherwood C, Abdelbaky O, Phillips C, Offenbacher $\mathrm{S}$, et al. Monitoring for periodontal inflammatory disease in the third molar region. Journal of Oral and Maxillofacial Surgery 2015;73(4):595-9.

Haug 2005 \{published data only\} Haug RH, Perrott DH, Gonzalez ML, Talwar RM. The American Association of Oral and Maxillofacial Surgeons Age-related Third Molar Study. Journal of Oral and Maxillofacial Surgery 2005;63(8):1106-14.

\section{Huang 2014 \{published data only\}}

Huang GJ, Cunha-Cruz J, Rothen M, Spiekerman C, Drangsholt M, Anderson L, et al. A prospective study of clinical outcomes related to third molar removal or retention. American Journal of Public Health 2014;104(4):728-34.

\section{Lindqvist 1982 \{published data only\}}

Lindqvist B, Thilander B. Extraction of third molars in cases of anticipated crowding in the lower jaw. American Journal of Orthodontics 1982;81(2):130-9.

\section{Moss 2007 \{published data only\}}

Moss KL, Beck JD, Mauriello SM, Offenbacher S, White RP. Third molar periodontal pathology and caries in senior adults. Journal of Oral and Maxillofacial Surgery 2007;65(1):103-8.

\section{Moss 2007a \{published data only\}}

Moss KL, Serlo AD, Offenbacher S, Beck JD, Mauriello SM, White RP. The oral and systemic impact of third molar periodontal pathology. Journal of Oral and Maxillofacial Surgery 2007;65(9):1739-45.

\section{Moss 2009 \{published data only\}}

Moss KL, Oh ES, Fisher E, Beck JD, Offenbacher S, White RP Jr. Third molars and periodontal pathologic findings in middle-age and older Americans. Journal of Oral and Maxillofacial Surgery 2009;67(12):2592-8.

\section{Moss 2013 \{published data only\}}

Moss KL, Offenbacher S, Beck JD, White RP. The presence of visible third molars negatively influences periodontal outcomes in the maternal oral therapy to reduce obstetric risk study. Journal of Oral and Maxillofacial Surgery 2013;71(6):988-93.

\section{Moss 2013a \{published data only\}}

Moss KL, Offenbacher S, Beck JD, White RP. The presence of visible third molars negatively influences periodontal outcomes in the maternal oral therapy to reduce obstetric risk study. Journal of Oral and Maxillofacial Surgery 2013;71(6):988-93. 
Nemcovsky 1997 \{published data only\}

Nemcovsky CE, Tal H, Pitaru S. Effect of non-erupted third molars on roots of approximal teeth. A radiographic, clinical and histologic study. Journal of Oral Pathology \& Medicine 1997;26(10):464-9.

\section{Offenbacher 2012 \{published data only\}}

Offenbacher S, Beck JD, Moss KL, Barros S, Mendoza L, White RP. What are the local and systemic implications of third molar retention?. Journal of Oral and Maxillofacial Surgery 2012;70(9):S58-65.

\section{Rahman 2009 \{published data only\}}

Rahman NA, Daud MKM, Yaacob MF, Yusoff A. Mandibular third molar impaction and dental caries among patients attending Hospital Universiti Sains Malaysia (HUSM). Internal Medicine Journal 2009;16(1):53-6.

\section{Venta 1993 \{published data only\}}

Venta I, Meurman JH, Murtomaa H, Turtola L. Effect of erupting third molars on dental caries and gingival health in Finnish students. Caries Research 1993;27(5):438-43.

\section{Venta 1993a \{published data only\}}

Venta I, Turtola L, Murtomaa H, Ylipaavalniemi P. Third molars as an acute problem in Finnish university students. Oral Surgery, Oral Medicine, and Oral Pathology 1993;76(2):135-40.

\section{Venta 2015 \{published data only\}}

Venta I, Kylatie E, Hiltunen K. Pathology related to third molars in the elderly persons. Clinical Oral Investigations 2015;19(8):1785-9.

\section{Additional references}

\section{Bienstock 2011}

Bienstock DA, Dodson TB, Perrott DH, Chuang SK. Prognostic factors affecting the duration of disability after third molar removal. Journal of Oral and Maxillofacial Surgery 2011;69(5):1272-7.

\section{Bradley 1996}

Bradley JG, Zia MJ, Hamilton N. Patient preferences for control in medical decision making: a scenario-based approach. Family Medicine 1996;28(7):496-501.

\section{Brokaw 1991}

Brokaw WC. The third molar question: when and why should we recommend removal?. Virginia Dental Journal 1991;68(4):18-21.

\section{Carter 2015}

Carter K, Worthington S. Morphologic and demographic predictors of third molar agenesis: a systematic review and meta-analysis. Journal of Dental Research 2015;94(7):886-94.

\section{Celikoglu 2010}

Celickoglus M, Miloglus O, Kazanci F. Frequency of agenesis, impaction, angulation, and related pathologic changes of third molar teeth in orthodontic patients. Journal of Oral and Maxillofacial Surgery 2010;68(5):990-5.

\section{Chuang 2007}

Chuang SK, Perrott DH, Susarla SM, Dodson TB. Age as a risk factor for third molar surgery complications. Journal of Oral and Maxillofacial Surgery 2007;65(9):1685-92.

\section{Dodson 2012}

Dodson TB. How many patients have third molars and how many have one or more asymptomatic, disease-free third molars?. Journal of Oral and Maxillofacial Surgery 2012;70(9):4-7.

\section{Fernandes 2006}

Fernandes MJ, Ruta DA, Ogden GR, Pitts NB, Ogston SA. Assessing oral health-related quality of life in general dental practice in Scotland: validation of the OHIP-14. Community Dentistry and Oral Epidemiology 2006;34(1):53-62.

\section{Fernandes 2010}

Fernandes MJ, Ogden GR, Pitts NB, Ogston SA, Ruta DA. Actuarial life-table analysis of lower impacted wisdom teeth in general dental practice. Community Dentistry and Oral Epidemiology 2010;38(1):58-67.

\section{Fisher 2010}

Fisher EL, Moss KL, Offenbacher S, Beck JD, White RP Jr. Third molar caries experience in middle-aged and older Americans: a prevalence study. Journal of Oral and Maxillofacial Surgery 2010;68(3):634-40

\section{Higgins 2011}

Higgins JPT, Green S (editors). Cochrane Handbook for Systematic Reviews of Interventions version 5.1.0 [updated March 2011]. The Cochrane Collaboration, 2011. www.cochranehandbook.org.

\section{Kandasamy 2009}

Kandasamy S, Rinchuse DJ. The wisdom behind third molar extractions. Australian Dental Journal 2009;54(4):284-92.

\section{Kapur 1972}

Kapur KK, Glass RL, Loftus ER, Alman JE, Feller RP. The Veterans Administration longitudinal study of oral health and disease. International Journal of Aging \& Human Development 1972;3:125-37.

\section{Knutsson 1992}

Knutsson K, Brehmer B, Lysell L, Rohlin M. General dental practitioners' evaluation of the need for extraction of asymptomatic mandibular third molars. Community Dentistry and Oral Epidemiology 1992;20(6):347-50.

\section{Kruger 2001}

Kruger E, Thomson WM, Konthasinghe P. Third molar outcomes from age 18 to 26: findings from a population-based New Zealand longitudinal study. Oral Surgery, Oral Medicine, Oral Pathology, Oral Radiology, and Endodontics 2001;92(2):150-5.

\section{McArdle 2012}

McArdle LW, Renton T. The effects of NICE guidelines on the management of third molar teeth. British Dental Journal 2012;213(8):394. 


\section{Mercier 1992}

Mercier P, Precious D. Risks and benefits of removal of impacted third molars. International Journal of Oral and Maxillofacial Surgery 1992;21(1):17-27.

\section{NICE 2000}

National Institute for Health and Clinical Excellence. NICE Technology Appraisal Guidance, TA1. Guidance on the Extraction of Wisdom Teeth. London: National Institute for Health and Clinical Excellence, 2000.

\section{Oenning 2015}

Oenning AC, Melo SL, Groppo FC, Haiter-Neto F. Mesial inclination of impacted third molars and its propensity to stimulate external root resorption in second molars - a conebeam computed tomographic evaluation. Journal of Oral and Maxillofacial Surgery 2015;73(3):379-86.

\section{RCS England 1997}

The Faculty of Dental Surgery of the Royal College of Surgeons of England. National Clinical Guidelines 1997. The management of patients with third molar (syn: wisdom) teeth. Current Clinical Practice and Parameters of Care. London: Royal College of Surgeons of England, 1997.

\section{Renton 2012}

Renton T, Al-Haboubi M, Pau A, Sepherd J, Gallagher JE. What has been the United Kingdom's experience with retention of third molars?. Journal of Oral and Maxillofacial Surgery 2012;70(9):48-57.

\section{SIGN 1999}

Scottish Intercollegiate Guidelines Network. Management of Unerupted and Impacted Third Molar Teeth. A National Clinical Guideline. SIGN Publication No 43. Edinburgh: Scottish Intercollegiate Guidelines Network, 1999.

\section{Song 1997}

Song F, Landes DP, Glenny AM, Sheldon TA. Prophylactic removal of impacted third molars: an assessment of published reviews. British Dental Journal 1997;182(9):339-46.

\section{Song $\mathbf{2 0 0 0}$}

Song F, O'Meara S, Wilson P, Golder S, Kleijnen J. The effectiveness and cost-effectiveness of prophylactic removal of wisdom teeth. Health Technology Assessment 2000;4(15):1-55.

\section{Sterne 2014}

Sterne JAC, Higgins JPT, Reeves BC, on behalf of the Development Group for ACROBAT-NRSI. A Cochrane Risk of Bias Assessment Tool for Non-Randomized Studies of Interventions (ACROBAT-NRSI), version 1.0.0, September 2014. http:// www.riskofbias.info (accessed 24 July 2016).

\section{Tate 1994}

Tate TE. Impactions: observe or treat?. Journal of Californian Dental Association 1994;22(6):59-64.

\section{Van der Sanden 2002}

Van der Sanden WJM, Mettes DG, Plasschaert AJ, Grol RP, Van't Hof MA, Knutsson K, et al. Effect of selected literature on dentists' decisions to remove asymptomatic, impacted lower third molars. European Journal of Oral Sciences 2002;110(1):2-7.

\section{Venta 1999}

Venta I, Turtola L, Ylipaavalniemi P. Change in clinical status of third molars in adults during 12 years of observation. Journal of Oral and Maxillofacial Surgery 1999;57(4):386-91.

\section{Venta 2004}

Venta I, Ylipaavalniemi P, Turtola L. Clinical outcome of third molars in adults followed during 18 years. Journal of Oral and Maxillofacial Surgery 2004;62(2):182-5.

\section{Worthington 2015}

Worthington $\mathrm{H}$, Clarkson J, Weldon J. Priority oral health research identification for clinical decision-making. Evidencebased Dentistry 2015;16(3):69-71.

\section{References to other published versions of this review \\ Ghaeminia 2012}

Ghaeminia H, Perry J, Nienhuijs MEL, Toedtling V, Hoppenreijs TJ M, van der Sanden WJM, Mettes T(G. Surgical removal versus retention for the management of asymptomatic impacted wisdom teeth. Cochrane Database of Systematic Reviews 2012, Issue 6. [DOI: 10.1002/14651858.CD003879.pub3]

\section{CHARACTERISTICS OF STUDIES}

Characteristics of included studies [ordered by study ID]

\section{Harradine 1998}

Methods Randomised controlled trial, parallel-group design, 2 treatment groups

Location: Bristol, UK

Single centre

Research aim: to investigate prospectively the effects of early extraction of third molars on late lower incisor crowding 
Harradine 1998 (Continued)

Participants
Inclusion criteria: individuals who had previously undergone orthodontic treatment but were no longer wearing orthodontic appliances or retainers. Orthodontic treatment comprised active treatment in the upper arch with only removable appliances or a single-arch fixed appliance, with no treatment or premolar extractions carried out in the lower arch. Individuals with crowded molars (third molars whose long axis and, therefore, presumed path of eruption was through the adjacent second molar)

Exclusion criteria: residual premolar extraction space

Number randomised: 164 individuals (55\% were female)

Number evaluated after 5 years: 77 individuals completed the trial ( $58 \%$ were female)

Age of entry to the trial (mean \pm standard deviation (SD)): 14 years 10 months \pm 16.2 months

Baseline characteristics: reported for overall group sample, not per study group

\begin{tabular}{ll}
\hline Interventions & $\begin{array}{l}\text { Group I: extraction of third molars ( } N=44 \text { evaluated) } \\
\text { Group II: retention of third molars ( } N=33 \text { evaluated) }\end{array}$ \\
\hline Outcomes & Outcome measures \\
- Little's irregularity index (LII). Mean differences \pm SD for change \\
- Intercanine width (ICW). Mean differences \pm SD for change \\
- Arch length (AL). Mean differences \pm SD for change \\
Length of follow-up: 5 years, mean length of follow-up was $66 \pm 12.6$ months \\
For the upper arch, investigators found no statistical differences between the 2 groups for the 3 out- \\
come variables \\
\hline Sample size calculation: not described \\
Analysis (linear modelling) of measurements of casts demonstrated no systematic differences between \\
individuals who completed the trial and those lost to follow-up \\
Baseline characteristics per study group for comparability at entry would have been appropriate
\end{tabular}

\section{Risk of bias}

Bias Authors' judgement Support for judgement

\begin{tabular}{|c|c|c|}
\hline $\begin{array}{l}\text { Random sequence genera- } \\
\text { tion }\end{array}$ & Low risk & Quote: "...a list of randomly generated numbers was used to allocate..." \\
\hline $\begin{array}{l}\text { Blinding of outcome as- } \\
\text { sessment }\end{array}$ & Low risk & $\begin{array}{l}\text { Quote: "the third molar status was unknown to the digitizer in order to elimi- } \\
\text { nate sub-conscious bias" }\end{array}$ \\
\hline Incomplete outcome data & High risk & $\begin{array}{l}\text { Quote: "...no systematic differences existed between those patients who en- } \\
\text { tered the trial and completed, and those who entered and did not complete" } \\
\text { Comment: } 53 \% \text { attrition overall, evaluation of } 44 \text { and } 33 \text { participants in extrac- } \\
\text { tion and non-extraction groups ( } 54 \% \text { and } 40 \% \text {, respectively) and reasons for } \\
\text { non-completion are given as "loss of contact with occupiers of their previous } \\
\text { address". No data are available on the gender balance of those who complet- } \\
\text { ed compared with those who did not, for each treatment group. Trial authors } \\
\text { report only the results of modelling of } 44 \text { non-responders. This trial would } \\
\text { seem to be at high risk of attrition bias }\end{array}$ \\
\hline
\end{tabular}


Harradine 1998 (Continued) $\begin{array}{ll}\text { Selective reporting } \quad \text { Unclear risk } & \text { Comment: The only outcomes reported in the paper are orthodontic indices. } \\ \text { No adverse effects of treatments or symptoms are reported }\end{array}$

Other sources of bias Low risk

Comment: More specific characteristics per study group for comparability at entry would have been appropriate

Nunn 2013

Prospective cohort study, part of Longitudinal Veterans Affairs Normative Aging Study, beginning in
1961 (Kapur 1972)
Location: United States (greater Boston area)
Research aim: to examine the association of third molar status with prevalent and incident caries and
periodontal outcomes in adjacent second molars

Participants

Healthy male patients who had both first and second molars present in at least 1 quadrant at baseline and had at least 1 follow-up. Examinations were performed every 3 years with duration to $>25$ years

Number of participants: 416 (804 third molars) from 1231 enrolled patients met the inclusion criteria Age of entry to the trial (mean \pm standard deviation $(\mathrm{SD}))$ : 45.8 years 9 months \pm 7.4 years

Baseline characteristics: Analyses were adjusted for baseline age, smoking status, education and baseline second molar measures

\begin{tabular}{ll} 
Interventions & $\begin{array}{l}\text { Retention of asymptomatic wisdom teeth compared with absence of wisdom teeth (previous extrac- } \\
\text { tion or agenesis at baseline) }\end{array}$ \\
\hline Outcomes & Second molar pathology \\
- Caries \\
- Distal probing depth $>4 \mathrm{~mm}$ \\
- Distal alveolar bone loss \\
These outcomes were measured every 3 years \\
Clinical outcomes (caries and probing depths $>4$ mm) measured by a trained, calibrated periodontist. \\
Radiological outcome (alveolar bone loss and caries) measured by board-certified oral and maxillofa- \\
cial surgeon and a board-certified oral and maxillofacial radiologist. Alveolar bone loss was measured \\
with a Schei ruler
\end{tabular}

Characteristics of excluded studies [ordered by study ID]

\begin{tabular}{ll}
\hline Study & Reason for exclusion \\
\hline Ades 1990 & Retrospective design \\
\hline Blakey 2009 & Short follow-up ( $<5$ years), not impacted third molars \\
\hline Coleman 2011 & Short follow-up ( $<5$ years $)$ \\
\hline
\end{tabular}




\begin{tabular}{|c|c|}
\hline Study & Reason for exclusion \\
\hline Dicus 2010 & Comparison of 2 different cohorts \\
\hline Dicus-Brookes 2013 & Only symptomatic third molars included \\
\hline Fisher 2012 & No comparison between retention and extraction or absence and presence of third molars \\
\hline Fisher 2013 & $\begin{array}{l}\text { No comparison between retention and extraction or absence and presence of third molars. Short } \\
\text { follow-up (<5 years) }\end{array}$ \\
\hline Garaas 2012 & No comparison between retention and extraction or absence and presence of third molars \\
\hline Golden 2015 & No comparison between retention and extraction or absence and presence of third molars \\
\hline Haug 2005 & No comparison between retention and extraction or absence and presence of third molars \\
\hline Huang 2014 & Short follow-up (<5 years) \\
\hline Lindqvist 1982 & Split-mouth study, which is an inappropriate design for evaluation of crowding of teeth \\
\hline Moss 2007 & Cross-sectional design \\
\hline Moss 2007a & Cross-sectional design \\
\hline Moss 2009 & Only obstetric patients with periodontal disease were included \\
\hline Moss 2013 & Only obstetric patients with periodontal disease were included \\
\hline Moss 2013a & Only obstetric patients with periodontal disease were included \\
\hline Nemcovsky 1997 & Removal of second molars (not third molars) \\
\hline Offenbacher 2012 & Cross-sectional design \\
\hline Rahman 2009 & Cross-sectional design \\
\hline Venta 1993 & $\begin{array}{l}\text { Data were not presented at patient level, but at sextant level. Participants who had wisdom teeth } \\
\text { removed during the study were excluded from analyses. The senior study author was contacted } \\
\text { successfully, but the complete dataset was not available }\end{array}$ \\
\hline Venta 1993a & Retrospective design \\
\hline Venta 2015 & No comparison between retention and extraction or absence and presence of third molars \\
\hline
\end{tabular}

\section{ADDITIONAL TABLES}

Table 1. Risk of bias assessed using ACROBAT-NRSI for Nunn 2013

\begin{tabular}{lll}
\hline Bias & $\begin{array}{l}\text { Authors' judge- } \\
\text { ment }\end{array}$ & Support for judgement \\
\hline Confounding & Serious risk & $\begin{array}{l}\text { Analyses were adjusted for baseline age, smoking status, education and baseline sec- } \\
\text { ond molar measures. However, oral health status such as oral hygiene and frequency of } \\
\text { dental checkups was not measured. These factors may contribute to the development of }\end{array}$ \\
\hline
\end{tabular}


Table 1. Risk of bias assessed using ACROBAT-NRSI for Nunn 2013 (Continued)

second molar pathology. However, "participants enrolled in the study returning for follow-ups are likely to be more health aware than their age-matched peers in the community and practice better health behaviors". This would suggest more motivated participants in this study compared with the overall population. Therefore the predicted direction of bias due to oral health status confounding favours retention (presence), and it is likely that the effect estimate would be even higher if was adjusted

$\begin{array}{ll}\begin{array}{l}\text { Selection of par- } \quad \text { Moderate risk } \\ \text { ticipants into the }\end{array} & \begin{array}{l}\text { Only male volunteers were included. However, gender is not expected to contribute to } \\ \text { the development of second molar pathology. Some participants lost third molars before } \\ \text { study }\end{array} \\ & \begin{array}{l}\text { the start of follow-up - in the target randomised trial for this study, participants would be } \\ \text { followed from the time the third molars were removed. As third molars were removed be- } \\ \text { fore the start of follow-up, a potentially important amount of follow-up time is missing }\end{array}\end{array}$

\begin{tabular}{|c|c|c|}
\hline $\begin{array}{l}\text { Measurement of } \\
\text { interventions }\end{array}$ & Low risk & $\begin{array}{l}\text { Intervention status was well defined and was based solely on information collected at the } \\
\text { time of intervention }\end{array}$ \\
\hline
\end{tabular}

\begin{tabular}{lll}
\hline $\begin{array}{l}\text { Departure from in- } \\
\text { tended interven- } \\
\text { tions }\end{array}$ & Moderate risk & $\begin{array}{l}\text { Switching of participants from retention to removal was likely, but this switching occurs } \\
\text { as part of the natural course of events }\end{array}$ \\
\hline Missing data & Serious risk & $\begin{array}{l}1231 \text { volunteers enrolled in the Dental Longitudinal Study beginning in } 1969 \text { (Kapur et al. } \\
\text { 1972), but only } 416 \text { analysed. This first study could not be obtained. Those with problems } \\
\text { from third molars were likely to have them removed before the study was initiated; there- } \\
\text { fore, this study has serious risk of bias due to missing data }\end{array}$
\end{tabular}

\begin{tabular}{lll}
\hline $\begin{array}{l}\text { Measurement of } \\
\text { outcomes }\end{array}$ & Moderate risk & $\begin{array}{l}\text { Caries, probing depths and alveolar bone loss were assessed clinically and on radi- } \\
\text { ographs adequately. Blinding was not possible, but we do not expect that non-blinding } \\
\text { would have influenced the results }\end{array}$ \\
\hline $\begin{array}{l}\text { Selection of re- } \\
\text { ported results }\end{array}$ & Moderate risk & $\begin{array}{l}\text { There is no evidence to suggest that multiple outcome measurements and/or multiple } \\
\text { analyses were conducted for each outcome. Only participants with both first and second } \\
\text { molars in at least } 1 \text { quadrant were included in the study, rather than the whole subset of } \\
\text { 1231 volunteers in the Dental Longitudinal Study. No a priori measurement or analysis } \\
\text { plan was included }\end{array}$ \\
\hline
\end{tabular}

\section{AP PEN DICES}

\section{Appendix 1. Cochrane Oral Health's Trials Register search strategy}

From June 2015, searches of the Cochrane Oral Health Group Trials Register were conducted using the Cochrane Register of Studies and the search strategy below:

1 (("third molar*" or "wisdom tooth" or "wisdom teeth" or "3rd molar*" or third-molar):ti,ab) AND (INREGISTER)

2 (retain* or retention or present* or presence):ti,ab

3 ((extract* or remov $^{\star}$ or absent $^{\star}$ or missing or absence):ti,ab) AND (INREGISTER)

$4 \# 2$ and \#3

5 (asymptom*:ti,ab) AND (INREGISTER)

6 ((symptomless or symptom-free or "symptom free"):ti,ab) AND (INREGISTER)

7 (("trouble free" or trouble-free):ti,ab) AND (INREGISTER)

8 (\#5 or \#6 or \#7) AND (INREGISTER)

9 \#4 or \#8

Surgical removal versus retention for the management of asymptomatic disease-free impacted wisdom teeth (Review)

Copyright @ 2016 The Cochrane Collaboration. Published by John Wiley \& Sons, Ltd. 
10 (\#1 and \#4 and \#9) AND (INREGISTER)

Previous searches of this database were conducted using the Procite software and the search strategy below:

(("third molar" OR "molar third" OR "wisdom teeth" or "wisdom tooth" OR "third-molar" or "3rd molar*") AND (impact* or unerupt*) AND ("Tooth extraction" or extract* or remov* or asymptom* or "trouble free" or trouble-free or "symptom free"))

\section{Appendix 2. Cochrane Central Register of Controlled Trials (CENTRAL) search strategy}

$\# 1$ [mh^"molar, third"]

\#2 ("third molar*" or "wisdom teeth" or "wisdom tooth" or "3rd molar*" or third-molar*)

\#3 \#1 or \#2

\#4 [mh^"Tooth extraction"]

\#5 (extract ${ }^{\star}$ or remov ${ }^{\star}$ or absent ${ }^{\star}$ or missing or absence)

\#6 \#4 or \#5

\#7 (retain* or retention or present* or presence)

\#8 \#6 and \#7

\#9 asymptom*

\#10 (symptomless or symptom-free or "symptom free")

\#11 (trouble-free or "trouble free")

$\# 12\{$ or \#9-\#11\}

$\# 13 \# 8$ or \#12

$\# 14 \# 3$ and \#13

\section{Appendix 3. MEDLINE Ovid search strategy}

1. Molar, Third/

2. ("third molar" or "wisdom tooth" or "wisdom teeth" or "3rd molar" or third-molar).mp.

3. 1 or 2

4. Tooth extraction/

5. (extract\$ or remov\$ or absent\$ or missing or absence).mp.

6.4 or 5

7. (retain\$ or retention or present\$ or presence).mp.

8. 6 and 7

9. asymptom\$.mp.

10. (symptomless or symptom-free or "symptom free").mp.

11. (trouble-free or "trouble free").mp.

12. or/9-11

13. 8 or 12

14. 3 and 13

Surgical removal versus retention for the management of asymptomatic disease-free impacted wisdom teeth (Review) 


\section{Appendix 4. Embase Ovid search strategy}

1. Molar tooth/

2. ("third molar\$" or "wisdom tooth" or "wisdom teeth" or "3rd molar\$" or third-molar\$).mp.

3. 1 or 2

4. Tooth extraction/

5. (extract\$ or remov\$ or absent\$ or missing or absence).mp.

6.4 or 5

7. (retain\$ or retention or presence).mp.

8. ((present or presence) adj3 (tooth or teeth or molar)).mp.

9. 7 or 8

10.6 and 9

11. asymptom\$.mp.

12. (symptomless or symptom-free or "symptom free").mp.

13. (trouble-free or "trouble free").mp.

14. or/11-13

15. 10 or 14

16. 3 and 15

\section{Appendix 5. ClinicalTrials.gov search strategy}

asymptomatic and third and molar

asymptomatic and wisdom and tooth

asymptomatic and wisdom and teeth

\section{Appendix 6. WHO International Clinical Trials Registry Platform search strategy}

asymptomatic and third molar

asymptomatic and wisdom tooth

asymptomatic and wisdom teeth

WHAT' S NEW

\begin{tabular}{lll}
\hline Date Event & Description
\end{tabular}

26 June 2016

New citation required and conclusions have changed

We added 1 new longitudinal study in this review update

Conclusions have changed. In the original review, we concluded that "watchful monitoring of asymptomatic impacted wisdom teeth may be a more prudent strategy". However, the available evidence is very low quality and there are insufficient data on which to base clinical decisions about the management of asymptomatic disease-free impacted wisdom teeth term risks and complications of retention/removal of asymptomatic disease-free impacted wisdom teeth are unlikely to be fea- 


$\begin{array}{lll}\text { Date Event Description } & \text { Den }\end{array}$

sible. We included non-randomised studies (NRSs) in this review update if they assessed long-term outcomes, i.e. over 5 years. The introduction of a new Cochrane Risk of Bias Tool for NRSs means we can now assess the risk of bias in NRSs more systematically

\section{HISTORY}

Protocol first published: Issue 1, 2002

Review first published: Issue 2, 2005

\begin{tabular}{lll}
\hline Date & Event & Description \\
\hline 14 May 2012 & $\begin{array}{l}\text { New citation required and conclusions } \\
\text { have changed }\end{array}$ & $\begin{array}{l}\text { As the result of changes in methodology, we have deleted 1 pre- } \\
\text { viously included study. We have revised the review conclusions } \\
\text { because evidence is insufficient to determine effects of prophy- } \\
\text { lactic extraction of asymptomatic wisdom teeth }\end{array}$ \\
\hline 14 May 2012 & New search has been performed & $\begin{array}{l}\text { New search was conducted. Title was changed to "Surgical re- } \\
\text { moval versus retention for the management of asymptomatic } \\
\text { impacted wisdom teeth" }\end{array}$ \\
\hline
\end{tabular}

\section{CONTRIBUTIONS OF AUTHORS}

For this update:

- Literature search update and study selection: Hossein Ghaeminia, John Perry, Marloes Nienhuijs, Verena Toedtling, Marcia Tummers, Theo Hoppenreijs, Wil van der Sanden, Dirk Mettes;

- Risk of bias and quality assessment: Hossein Ghaeminia, John Perry, Marcia Tummers, Marloes Nienhuijs, Verena Toedtling, Theo Hoppenreijs, Wil van der Sanden, Dirk Mettes; and

- Editing of the review: Hossein Ghaeminia, John Perry, Marcia Tummers, Marloes Nienhuijs, Verena Toedtling, Theo Hoppenreijs, Wil van der Sanden, Dirk Mettes.

\section{DECLARATIONS OF INTEREST}

The participating review authors declare that they have no financial conflicts of interest, nor do they have any associations with industry regarding the topic of this review.

Hossein Ghaeminia: none known John Perry: none known Marloes EL Nienhuijs: none known Verena Toedtling: none known Marcia Tummers: none known Theo J M Hoppenreijs: none known Wil JM van der Sanden: none known Theodorus (Dirk) G Mettes: none known

\section{SOURCES OF SUPPORT}

\section{Internal sources}

- Radboud University Medical Centre, Nijmegen, Netherlands.

\section{External sources}

- School of Dentistry, The University of Manchester, UK.

Surgical removal versus retention for the management of asymptomatic disease-free impacted wisdom teeth (Review) 
- National Institute for Health Research (NIHR), UK.

This project was supported by the NIHR, via Cochrane Infrastructure funding to Cochrane Oral Health. The views and opinions expressed therein are those of the review authors and do not necessarily reflect those of the Systematic Reviews Programme, NIHR, NHS or the Department of Health

- Cochrane Oral Health Global Alliance, Other.

Through our Global Alliance (ohg.cochrane.org/partnerships-alliances), Cochrane Oral Health has received support from British Association for the Study of Community Dentistry, UK; British Association of Oral Surgeons, UK; British Orthodontic Society, UK; British Society of Paediatric Dentistry, UK; British Society of Periodontology, UK; Canadian Dental Hygienists Association, Canada; Centre for Dental Education and Research (CDER), India; Mayo Clinic, USA; National Center for Dental Hygiene Research \& Practice, USA; New York University College of Dentistry, USA; NHS Education for Scotland (NES) and Royal College of Surgeons of Edinburgh, UK

\section{DIFFERENCES BETWEEN PROTOCOLAND REVIEW}

- Title - we added 'disease-free'.

- Types of participants. In the original protocol, the intention was to include only studies on adult participants (over 17 years of age). However, review authors identified no suitable trials. It was therefore decided to expand the remit to include studies on adolescent participants. The change in the age of participants is not expected to have any clinical implications because little clinical difference has been noted between adolescents ( 14 to 17 years of age) and young adults ( 18 to 25 years of age).

- Types of studies. Long-term outcomes of retention/removal of asymptomatic disease-free impacted wisdom teeth are extremely unlikely to be studied in randomised controlled trials (RCTs). Therefore, we considered non-randomised studies (NRSs) for inclusion in this review update, if outcomes were measured with follow-up of at least five years.

- Types of interventions. Presence and absence of wisdom teeth were added to investigate the long-term outcomes of retention or removal of wisdom teeth. This enabled us to study the effects of absence or presence of wisdom teeth on adjacent structures such as the second molar.

- Types of outcomes. More than 15 years after the initial protocol, many publications have addressed periodontitis as a possible undesirable effect of retention of wisdom teeth. Furthermore, attention to medication/radiotherapy-related osteonecrosis of the jaw associated with surgical extractions is increasing. Therefore, we added these secondary outcomes to the methods. We expanded other outcomes.

- Because we considered NRSs for inclusion in the review update, we used the Cochrane Risk of Bias Assessment Tool for Non-Randomized Studies of Interventions (ACROBAT-NRSI) for the risk of bias assessment of NRSs (Sterne 2014).

- As we were including NRSs, we executed the search without an RCT study design filter, and the results of the full search are reported in Figure 1.

\section{N DEX TERMS}

\section{Medical Subject Headings (MeSH)}

Asymptomatic Diseases; Molar, Third [*surgery]; Prospective Studies; Randomized Controlled Trials as Topic; Tooth Extraction [*methods]; Tooth, Impacted [* surgery]; Watchful Waiting

\section{MeSH check words}

Adolescent; Adult; Aged; Aged, 80 and over; Humans; Middle Aged 